\title{
Sagittal fractures of the palate: A new method of treatment
}

\author{
Mark D Wells MD FRCSC, Scott Oishi MD, Mustafa Sengezer MD \\ Division of Plastic Surgery, Department of Surgery, University of Kentucky Chandler \\ Medical Center, Lexington, Kentucky, USA
}

\begin{abstract}
MD Wells, S Oishi, M Sengezer. Sagittal fractures of the palate: A new method of treatment. Can J Plast Surg 1995;3(2):87-92. A new technique is described for stabilizing complex vertical fractures of the maxilla. Advantageous use of the comminuted fracture pattern of the maxillary buttresses allows the maxilla to be divided into two parts at the Le Fort I level. With intermaxillary fixation applied, stabilization is achieved by applying miniplate fixation to the nasal side of the hard palate. The maxilla is reduced to the previously stabilized anterior midfacial buttresses with plates and screws. Comminuted segments of defects in the anterior buttresses are replaced with contoured calvarial grafts. This method has the advantage of maintaining transverse palatal width in a rigid fashion without the need for further osteotomies. It has satisfactorily restored preinjury occlusal relationships in six patients, without the need for dental splints. In no instance has hardware extrusion occurred after fixation.
\end{abstract}

Key Words: Fracture fixation, Maxilla

\section{Fractures sagittales du palais, nouveau mode de traitement}

RÉSUMÉ : Une nouvelle technique est ici décrite pour la stabilisation des fractures verticales complexes du maxillaire. L'utilité du mode de fracture comminutive des piliers maxillaires permet au maxillaire d'être divisé en deux au niveau de la fracture de type Le Fort I. Avec l'application d'une fixation intermaxillaire, la stabilisation s'obtient au moyen d'une miniplaque de fixation du côté nasal de la voûte palatine. Le maxillaire est réduit aux piliers hémifaciaux antérieurs préalablement stabilisés à l'aide de plaques et de vis. Les segments comminutifs des défauts des piliers antérieurs sont replacés à l'aide de greffons crâniens ourlés. Cette méthode a l'avantage de maintenir avec rigidité la largeur du palais transverse sans recours à d'autres ostéotomies. Elle a permis la restauration de l'occlusion telle qu'elle était avant l'accident chez six patients, sans recours à des traitements d'orthodontie. Aucun cas d'extrusion des appareils n'est survenu après la fixation.

Traumatic injuries to the midface occasionally result in fractures of the hard palate. These fractures may occur as isolated injuries but are more commonly associated with comminuted midfacial fractures (1).

The literature describes numerous methods of preventing collapse of the dentoalveolar segments. Classically, this problem has been handled by closed reduction 
or by suspension wires used with an acrylic splint and intermaxillary fixation to maintain the alignment of the maxillary dentition (1). More recently, authors have advocated the use of open reduction and internal fixation with interosseous wires to stabilize these complex fractures $(1,2)$. Unfortunately, because of the intrinsic instability of the fracture pattern, rotation of the maxillary segments is still possible when open reduction is used (1).

In the mid 1980s, Gruss et al $(3,4)$ and Manson et al (5) advocated extensive plate-and-screw fixation for midfacial fractures. The advantage of this technique was that it maintained midfacial projection, vertical length, and width, while also allowing for early release of intermaxillary fixation. Manson applied the principles of rigid fixation to vertical maxillary fractures by using a transpalatal approach to the fracture (6). However, this technique required the release of intermaxillary fixation to apply the required hardware, thus introducing the possibility of malocclusion during repair. Additionally, in $10 \%$ of patients, the plate was exposed in the roof of the mouth.

We describe a new technique for stabilizing complex vertical fractures of the maxilla: plating from the nasal side of the fracture. This method maintains rigid transverse palatal width without the complication of hardware exposure.

\section{Vertical buttresses of the face}

\section{FACIAL ANATOMY}

The midface consists of sinus cavities reinforced vertically and horizontally by pillars or buttresses of bone $(7,8)$. As outlined by Gruss et al $(3,4)$, the goal in the treatment of Le Fort fractures is correct anatomic restoration of the maxilla in relation to the cranial base above and the mandible below. The primary vertical buttresses of the face are the two medial buttresses (nasomaxillary buttresses), the two lateral buttresses (zygomaticomaxillary buttresses), and the two posterior buttresses (pterygomaxillary buttresses) of the maxilla. Clinically, we confine our reconstructive efforts to the four anterior buttresses (two lateral and two medial). No reconstruction is required for the posterior buttresses.

\section{Transverse buttresses of the face}

Although reconstructing the anterior buttresses ensures adequate midfacial height and occlusion, it fails to address the problem of midfacial width. A third transverse dimension must be considered if we are to treat patients with Le Fort fractures adequately. If the transverse dimension is not properly reconstructed, the patient may be left with increased facial width, decreased facial projection, midfacial asymmetry, and cross-bite at the occlusal level.

Just as the vertical dimensions of the face are maintained by the medial, lateral and posterior vertical buttresses outlined above, facial width is dependent on three transverse buttresses of the midface. These horizontal buttresses provide support to the vertical buttresses by uniting the medial and lateral buttresses superiorly and inferiorly (9).

The most superior transverse buttress is the frontal bar, consisting of the strong superior orbital rims of the frontal bone. The frontal bar forms the roof, both medial walls and both lateral walls of the orbit. Restoration of the frontal bar is key to restoring the preinjury anatomy of patients with significant comminution in this region. 
Similar transverse buttresses occur at the infraorbital level. This strong bony buttress consists of the zygomatic arch, the body of the zygoma, and the thickened infraorbital rims. The inferior orbital rim is often comminuted in high-velocity injuries, frequently precluding accurate anatomic reduction in this region. As outlined by Gruss and Phillips (10), reconstruction of the outer midfacial framework (consisting of the zygomatic arch, the body and the lateral infraorbital rim) will allow us to reconstruct comminuted segments with contoured bone grafts. By restoring correct midfacial width at the level of the arch, we assure proper midfacial projection and transverse width. Thus the zygomatic arch is the key to establishing midfacial width at the subcranial level (11). Allowing the arch to bow outward during reduction, rather than passing directly posteriorly from the body of the zygoma to the zygomatic process of the temporal bone, creates increased facial width and decreased facial projection.

At the occlusal level, transverse width is determined by the maxillary alveolus and the supporting palatal processes of the maxilla. Anteriorly, the maxillary alveolus, the floor of the pyriform aperture, the premaxilla and the strong anterior nasal spine combine to form a strong, horseshoe-shaped transverse buttress. Posteriorly, the maxillary tuberosities, the palatal shelves, the vomer and the posterior nasal spine support the posterior aspect of the arch transversely.

\section{FRACTURE PATTERNS}

Sagittal fractures of the maxilla are essentially fractures through the inferior horizontal buttress of the midface. Fractures through this buttress result in instability of this buttress with lingual tipping of the dentoalveolar maxillary segments. The result is unilateral or bilateral posterior cross bites (12), oral nasal fistula and possibly velopharyngeal incompetence.

The two maxilla are joined in the midline by a strong midpalatal suture. This suture begins to ossify during early adolescence and has generally fused completely by the time the patient is 30 years of age (13). Thus, in the adult population, most fractures are parasagittal, occurring in the thinner bone adjacent to this thickened ossified suture (6). During childhood, the suture is open; thus force applied to the palate tends to split the bone in the midline between the two unfused palatal shelves. More unusual fracture patterns have been described, including transverse fractures, which divide the palate in the coronal plane, and palatoalveolar fractures, which include dentoalveolar fractures. Isolated fractures of the maxillary tuberosity rarely warrant fixation. Almost all Le Fort fractures with sagittal splinting are associated with significant comminution and dislocation of the fracture segments (14) (Figure 1). We have used this comminution to our advantage. By using pre-existing fractures at the Le Fort I level, we are able to apply fixation from the nasal side and to secure the fixation by using intermaxillary fixation. The repair of hard palate injuries is addressed in the same fashion as other facial fractures, ie, with the concept of buttress realignment, miniplate fixation and contoured bone grafts if required. By rigidly fixing palatal injuries we restore central facial width, which can serve as a template for mandibular articulation. 

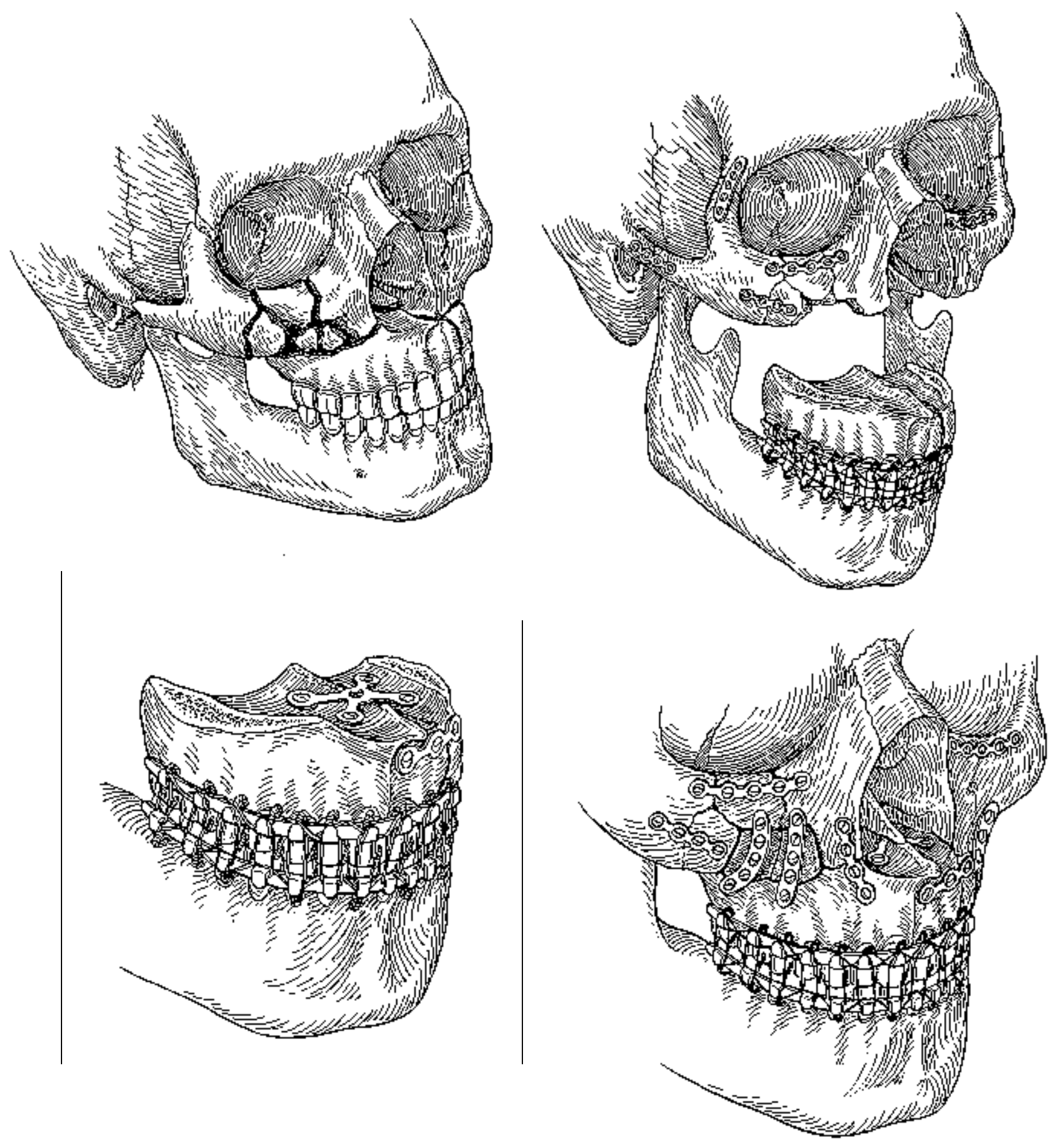

Figure 1) (Top left) Panfacial injury demonstrating comminution of the medial and lateral buttresses in association with a transverse palatal fracture. (Bottom left) Stabilization of the upper midface. Parasagittal palatal fracture is demonstrated after the maxilla has been divided into two parts. Note that mandibular maxillary fixation has been applied. (Top right) After division of the maxilla, plates are applied to the nasal side of the palate and the pyriform aperture. (Bottom right) Maxilla is reduced to upper midface. Defects in the anterior buttresses are replaced with contoured calvarial bone grafts J PLAST SURG VOL 3 NO 2 SUMMER 1995 


\section{OPERATIVE TECHNIQUE}

After general anaesthesia is administered through an orotracheal tube, the patient's head is prepared and draped for a standard bicoronal incision. Intermaxillary fixation is applied and the armored tube is brought out behind the third molar. The tube is then wired into the arch bars to prevent accidental dislodgment during the procedure. Because our technique of fixation is stable, only rarely have we found it necessary to resort to a preliminary tracheostomy before applying intermaxillary fixation. The only exceptions in the series have been in patients with multisystem failure or significant neurologic injury; these patients required prolonged postoperative ventilatory support.

A standard bicoronal incision is made, dissecting in the extraperiosteal plane. Approximately $4 \mathrm{~cm}$ above the supraorbital rim, the dissection proceeds subperiosteally, to protect the superior orbital nerves and supratrochlear vessels. The orbital roof is stripped subperiosteally, and care is taken not to remove the medial canthal insertions from their orbital insertion. Temporally, at the level of the supraorbital margin, the dissection is taken below the superficial temporal fascia to preserve the frontal branch of the facial nerve. The lateral orbital margin, the zygomatic arch and the body of the zygoma are then exposed subperiosteally, exposing the underlying fracture pattern.

The orbital floor is exposed through bilateral subconjunctival incisions extended with an inferior lateral canthotomy to provide the necessary exposure. All four edges of the defects in the orbital floor are identified under direct vision. Next, an upper buccal sulcus-degloving midfacial incision is made, exposing the comminuted medial and lateral buttresses of the maxilla.

With a periosteal elevator, the nasal mucosa is elevated from the floor of the nose and the inferior aspect of the septum. A septal osteotome is used to separate the cartilaginous septum and the perpendicular plate of the ethmoid from the underlying vomer. Because the medial and lateral buttresses are generally comminuted as a result of the force of the initial impact, it is a simple matter to use digital compression to separate the maxilla into two pieces. To date, we have not found it necessary to perform an osteotomy of the pterygomaxillary buttress to allow separation of the maxilla (Figure 1).

After the maxilla has been divided and the palatal fracture has been reduced under direct vision, a final check of the occlusion is made. If the occlusion is satisfactory, stability is achieved by using a four-hole miniplate placed from the nasal side of the palate. More recently, we have successfully achieved fixation by using four-hole three dimensional miniplates and $2 \mathrm{~mm}$ self-tapping screws.

After reduction has been achieved at the level of occlusion, attention is directed to the upper midface. The face is reconstructed in a rostral-to-caudal direction, building from stable bone to unstable bone in a sequential fashion. A transosseous wire is placed at the frontozygomatic suture to serve as a temporary point of fixation. Transverse width is set by reducing and plating the zygomatic arches under direct vision. The infraorbital rim is plated, and a final check of the zygomatic reduction is made by looking at the lateral orbital margin. As outlined by Gruss (10), in all but the most severe craniofacial injuries the orbital process of the frontal bone remains as a useful three-dimensional landmark for checking zygomatic reduction. With an anatomic reduction, there should not be a step off between the orbital process of the frontal and zygomatic bones. If a gap is present, the reduction is not satisfactory. Usually, the problem is rotation of the 
zygoma in the coronal plane, with resultant increased transverse width and decreased facial reduction. Once an adequate zygomatic reduction has been achieved, the frontozygomatic suture is fixed with microplate fixation.

After the transverse width of the midface has been established at the supraorbital, infraorbital and occlusal levels, the medial and lateral buttresses are reduced to the palatal fragment at the Le Fort I level and plated with miniplates and screws. If one of the buttresses is significantly comminuted, it is replaced with a contoured calvarial bone graft and stabilized with rigid fixation. A final plate is placed across the fracture line between the anterior teeth, taking care to avoid the roots of the teeth at the level of the pyriform aperture.

Any nasoethmoid or orbital fractures are treated in the standard fashion, liberally using calvarial bone grafts as required to repair defects in the facial skeleton. All incisions are closed and intermaxillary fixation is released to ensure a proper occlusal relationship.

\section{RESULTS}

We have used this method over a two-year period to treat seven patients with parasagittal fractures of the palate (Table 1). The average age of these patients was 17 years (range, 14 to 29 years). Half of the patients were male. Our average follow-up has been 11 months. Postoperative occlusion has been satisfactory in all cases. Our only complication was a palatal fistula that developed in the perioperative period. The fistula responded to secondary attempts at closure.

TABLE 1: Summary of patients with palatal fractures treated with the described technique

\begin{tabular}{|c|c|c|c|}
\hline Patient & $\begin{array}{l}\text { Age } \\
\text { (years) }\end{array}$ & Fracture pattern & Complications \\
\hline A & 18 & $\begin{array}{l}\text { Bilateral blowouts, bilateral zygomas, Le Fort I } \\
\text { palate }\end{array}$ & None \\
\hline B & 14 & $\begin{array}{l}\text { Nasoethmoid, zygoma, palate, mandible and } \\
\text { maxilla }\end{array}$ & None \\
\hline $\mathrm{C}$ & $<+>7$ & Le Fort I and III, palate, mandible & Palatal fistula \\
\hline $\mathrm{D}$ & 19 & $\begin{array}{l}\text { Le Fort I, bilateral zygomas, dento-alveolar, palate, } \\
\text { mandible }\end{array}$ & None \\
\hline $\mathrm{E}$ & 19 & Le Fort I and III, palate & None \\
\hline $\mathrm{F}$ & 14 & $\begin{array}{l}\text { Le Fort I and III, nasoethmoid, orbital, mandible, } \\
\text { palate, }<->\text { C-spine, ribs }\end{array}$ & None \\
\hline G & 29 & Le Fort I and III, palate & None \\
\hline
\end{tabular}




\section{CASE REPORT}

An 10-year-old boy suffered multiple long bone fractures and extensive injuries to the facial skeleton as a result of a motor vehicle accident (Figure 2). Facial fractures included a nasoethmoid fracture, bilateral blow-out fractures of the orbit, bilateral zygomatic fractures, fractures at the Le Fort I level bilaterally, a sagittal palatal fracture, a right mandibular body fracture and a left condyle injury. Over the next several hours the visual acuity in the patient's right eye began to deteriorate, despite the administration of intravenous steroids. The patient underwent emergent evacuation of a right optic nerve hematoma and optic nerve fenestration. Intermaxillary fixation was applied, and a coronal incision was performed. The patient underwent open reduction and internal fixation of both zygomas, bilateral repair of the orbital floors, and primary nasal bone grafting to provide structural stability to the nasoethmoid region.
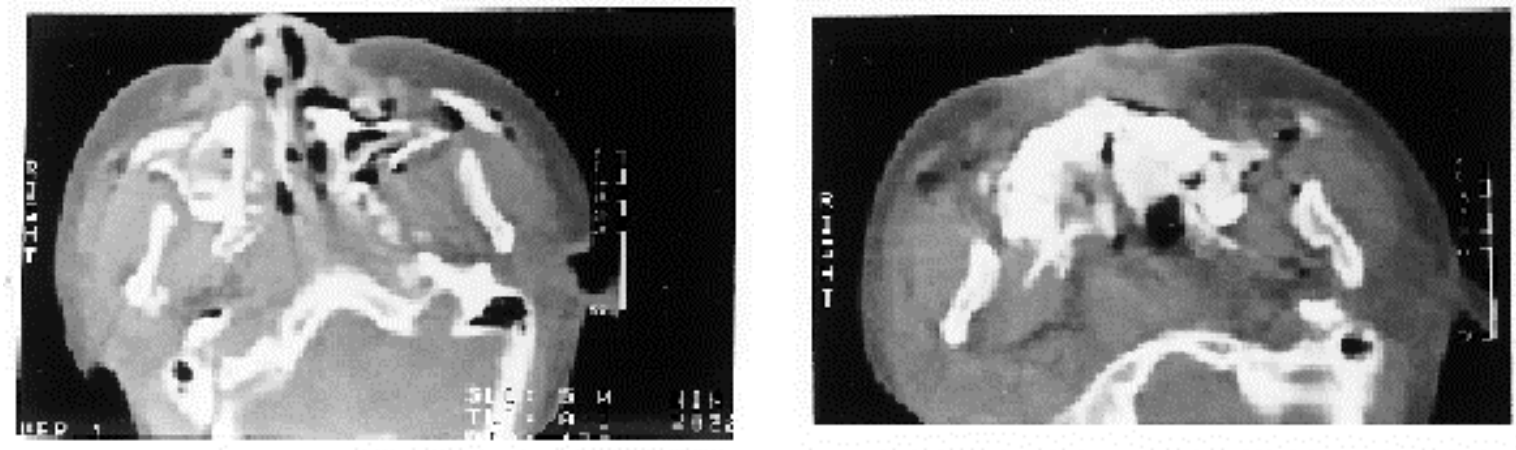

Figure 2) Axial computerized tomographic (CT) scans demonstrating extensive comminution of the midface (top) with parasagittal fracture of the maxilla (bottom)

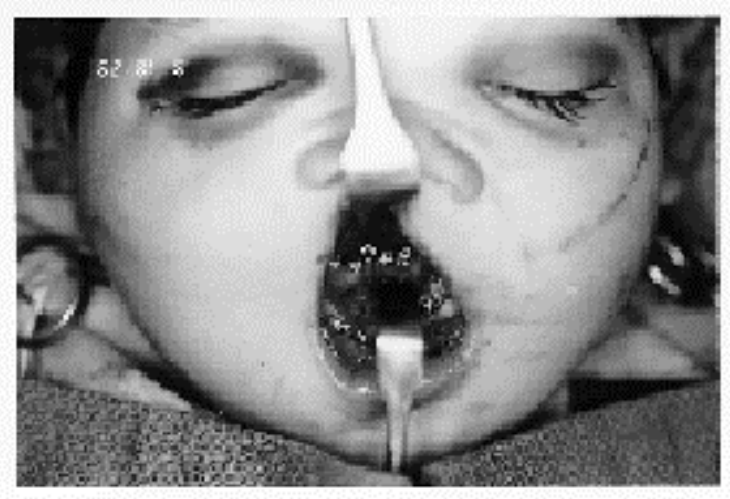

Figure 3) Intraoperative view demonstrating application of plate to the nasal side of the palate 
The maxillary arch bar was cut at the level of the palatal split to allow manipulation of the two palatal halves. Using pre-existing fractures in the medial and lateral buttresses, the maxilla was easily divided into two parts after the nasal septum had been released. Under direct vision, the palatal segments were reduced and plated with a five-hole miniplate (Figure 3). A second plate was placed across the fracture at the level of the pyriform aperture. The palatal fragment was then reduced to the upper midface, and miniplates were applied.

At one-year follow-up, the patient's occlusion is class I with no evidence of crossbite or palatal collapse. His maximum incisal opening is $33 \mathrm{~mm}$. The vision in the affected right eye is $20 / 20$ with no evidence of enophthalmos bilaterally. His transverse width and facial projection are normal.

\section{DISCUSSION}

Undisplaced maxillary fractures in the dentulous patient can be satisfactorily immobilized with an arch bar and intermaxillary fixation to stable mandibular dentition. However, maxillary fractures are commonly the result of high velocity motor vehicle accidents, which result in significant comminution and displacement of the underlying facial skeleton. Treatment with suspension wires and intermaxillary fixation often results in undesirable clinical outcomes, including loss of midfacial height and projection and anterior open bite.

The classic patterns of midfacial fractures as delineated by Le Fort are rarely encountered in clinical practice (2). Most of these injuries do not occur along the usual lines of weakness in the facial skeleton, but rather consist of combinations of Le Fort fractures. Recognition of this fact has served as an impetus to develop a more comprehensive approach to the treatment of high-energy maxillary injuries.

Historically, palatal fractures have been treated with a number of techniques. These have included intermaxillary fixation, acrylic palatal splints (1), K-wire fixation, circummolar wires, interosseous wires, and transverse and longitudinal mattress wires $(1,15,16)$. More recently, rigid fixation of the palate has been described $(6,17)$. Rigid fixation of palatal fractures is performed through mucosal lacerations or incisions placed over the fracture sites. The oral mucosa is elevated to allow placement of two-hole miniplates fixed with $2 \mathrm{~mm}$ screws. One or two plates are placed on each side of the fracture. The fracture is reduced with manual compression and the second screw is placed on the opposite side of the fracture. Stabilization is then performed at the pyriform aperture and the medial and lateral buttresses of the maxilla.

Others (18) share our view that this technique is conceptually flawed. It is difficult to imagine that an accurate anatomic reduction could be obtained by having an assistant press the maxillary alveolar segments together while the fixation is applied to the palatal surface. The result would be approximation of the patient's preinjury occlusion, because the mandibular dentition is not used as a guide for reduction. The most accurate way to reduce the fracture fragments would be to place the patient into intermaxillary fixation before the application of the hardware. Plate-and-screw fixation is much more technique sensitive than closed reduction or even open reduction with interosseous wire fixation. Rigid fixation is nonforgiving, because it does not allow for postoperative adjustment of the position of the maxilla by the patient's own muscle pull or with orthodontic appliances. Therefore, any error in maxillary position will 
permanently fix the maxilla into an undesirable relationship to the skull base superiorly and the mandible below. We believe that the use of transnasal palatal fixation improves stability, accurately defines maxillary arch width, and limits rotation of dentoalveolar segments. It allows the surgeon to obtain transverse stability of the fracture fragments while intermaxillary fixation is in place, thus assuring an accurate occlusal relationship with the mandibular dentition. Because no models, splints or prolonged intermaxillary fixation are required, early oral rehabilitation can be achieved. No specialized laboratory equipment or surgical instrumentation is required other than a standard maxillary plating system. We have had no problems with devascularization of the maxillary segments because we do not disrupt the palatal mucosa and we take care to preserve the posterior palatine blood supply. One of our patients developed a palatal fistula that required secondary revisional surgery, but in no case were we faced with the problem of exposed hardware within the oral cavity.

We do not advocate this technique for simple palatal fractures without comminution of the medial and lateral anterior buttresses. Patients with these fractures are more easily treated with a palatal splint and a course of intermaxillary fixation. In our opinion, an elective Le Fort I osteotomy for surgical exposure is not indicated. However, after high velocity maxillary injuries with comminution of the four anterior buttresses, it is a simple matter to separate the maxilla to apply the required fixation.

None of our patients experienced significant bleeding after separation of the maxilla, but we realize that this is a potential complication of the technique. Additionally, the longterm effect of palatal plating on the growing maxilla remains to be determined. Perhaps the development of resorbable plating systems will overcome some of our natural reluctance to apply this technique to children.

\section{REFERENCES}

1. Manson PN, Shack RB, Leonard LG, Su CT, Hoopes JE. Sagittal fractures of the maxilla and palate. Plast Reconstr Surg 1983;72:484-9.

2. Le Fort R. Étude experimental sur les fractures de la mâchoire supérieure. Parts I, II, III. Rev Chir Paris 1901;23:201,360,470.

3. Gruss JS, Mackinnon SE, Kassel EE, Cooper PW. The role of primary bone grafting in complex craniomaxillofacial trauma. Plast Reconstr Surg 1985;75:17-24.

4. Gruss JS, Mackinnon SE. Complex maxillary fractures: role of buttress reconstruction and immediate bone grafts. Plast Reconstr Surg 1986;78:9-22.

5. Manson PN, Crawley WA, Yaremchuk MJ, Rochman GM, Hoopes JE, French JH. Midface fractures: advantages of immediate extended open reduction and bone grafting. Plast Reconstr Surg 1985;76:1-12.

6. Manson PN, Glassman D, Vanderkolk C, Petty P, Crawley WA. Rigid stabilization of sagittal fractures of the maxilla and palate. Plast Reconstr Surg 1990;85:711-7.

7. Sicher H, Du Brul EL. Oral Anatomy, 5th edn. St Louis: CV Mosby Co, 1970:78. 8. Manson PN, Hoopes JE, Su CT. Structural pillars of the facial skeleton: an approach to the management of Le Fort fractures. Plast Reconstr Surg 1980;66:54-62.

9. Stanley RB Jr, Nowak GM. Midfacial fractures: importance of angle of impact to horizontal craniofacial buttresses. Otolaryngol Head Neck Surg 1985;93:186-92. 
10. Gruss JS, Phillips JH. Rigid fixation of zygomatic fractures. In: Yaremchuck MJ, Gruss JS, Manson PN, eds. Rigid Fixation of the Craniomaxillofacial Skeleton. Boston: Butterworth Heinemann, 1992:274.

11. Stanley RB Jr. The zygomatic arch as a guide to reconstruction of comminuted malar fractures. Arch Otolaryngol Head Neck Surg 1989;115:1459-62.

12. Stanley RB Jr. Rigid fixation of fractures of the maxillary complex. Facial Plast Surg 1991;7:176.

13. Perrson M, Thilander B. Palatal suture closure in man from 15 to 35 years of age. Am J Orthod 1977;72:42-52.

14. Gruss JS. Discussion: sagittal fractures of the maxilla and palate. Plast Reconstr Surg 1983;72:489.

15. Davis DG, Constant E. Transverse palatal wire for treatment of vertical maxillary fractures. Plast Reconstr Surg 1971;48:191-3.

16. Quinn JH. Open reduction and internal fixation of vertical maxillary fractures. J Oral Surg 1968;26:167-71.

17. Rimell F, Marentette LJ. Injuries of the hard palate and the horizontal buttress of the midface. Otolaryngol Head Neck Surg 1993;109:499-505.

18. Werther JR. Fixation of sagittal fractures of the maxilla [letter]. Plast Reconstr Surg 1991;87:198-9. 